Journal of Applied Veterinary Sciences, 7 (1): 53-57 (January, 2022).

ISSN: Online: 2090-3308, Print: 1687-4072

Journal homepage : https://javs.journals.ekb.eg

\title{
Effective Vaccination Program for Squabs from Vaccinated and NonVaccinated Pigeons with Tissue Culture Adapted Pigeon Pox Live Attenuated Vaccine Regarding Maternal Immunity
}

\author{
Kafafy, M. H. and Ayatollah, I. Ibrahim* \\ Pox Vaccines Research Department, Veterinary Serum and Vaccine Research Institute, Agricultural \\ Research Center (ARC), Cairo, Egypt. \\ *Corresponding Author: Ayatollah, I. Ibrahim, E-Mail: aytollah@ hotmail.com
}

\begin{abstract}
In this study, the duration of immunity as well as maternally derived antibodies (MDA) induced by the innovated tissue culture pigeon pox vaccine (TC-PPV) were evaluated for the first time. It was found that the postvaccinal reaction was more prominent in pigeons vaccinated with egg-adapted PPV (EG-PPV) (100\%) than in pigeons vaccinated with TC-PPV $(88 \%)$. The duration of induced immunity was higher using EG-PPV (1 year with a peak of neutralizing antibodies index 3.25 while it was 2.75 using TC-PPV) after 1 month of vaccination. MDA in squabs of vaccinated dams with TC-PPV maintained the protective level of antibodies up to 3 weeks post-hatching (WPH) with $100 \%$ protection against a challenge. In contrast, in squabs of vaccinates with EGPPV, it remained up to $4 \mathrm{WPH}$ with $90 \%$ protection. Such antibody levels hinder the immune response to vaccination with TC-PPV resulting in vaccination failure with $40 \%$ protection for squabs of TC-PPV vaccinated dams at $3^{\text {rd }} \mathrm{WPH}$ and $60 \%$ protection for squabs of EG-PPV vaccinated dams at $4^{\text {th }}$ WPH reflecting the successive vaccination at the $4^{\text {th }} \mathrm{WPH}$ and $5^{\text {th }} \mathrm{WPH}$, respectively for hatched squabs with $80 \%$ protection in both groups while in squabs of unvaccinated dams; the vaccination with TC-PPV appears to be protective from ${ }^{2 n d}$ WPH with $100 \%$ protection. In addition, this study recommends revaccination of pigeons with TC-PPV after 10 months and vaccination of their squabs not before $4 \mathrm{WPH}$ to avoid vaccination failure by MDA.
\end{abstract}

Keywords: Egg adapted Pigeon Pox Vaccine (EG-PPV), Maternal derived antibodies (MDA), Pigeon Pox vaccine (PPV), Virus neutralization test (VNT).
Original Article:

DOI:10.21608/javs.2021.104273.1113

Received: 03 November, 2021. Accepted : 16 December, 2021. Published in January, 2022.

This is an open access article under the term of the Creative Commons Attribution 4.0 (CC-BY) International License . To view a copy of this license, visit:

http://creativecommons.org/licenses/by/4.0/

J. Appl. Vet. Sci., 7 (1 ): 53-57.

\section{INTRODUCTION}

Pigeon pox (PP) is a viral disease affecting pigeons caused by Pigeon pox virus (PPV), a doublestranded DNA virus of family Poxviridae and genus Avipoxvirus (APV) along with fowlpox virus (FPV) (Andraw, 2012 and OIE, 2019 ).

The disease has an economic impact in pigeon rearing systems by the losses of infected pigeons, especially in young pigeon pullets (Abdallah and Hassanin, 2013) even when affected by cutaneous form around the mouth and eyes with ulcerated oral cavity making pigeons unable to eat or drink causing starvation and dehydration leading to death (Mehmood et al., 2021), while the diphtheria form is characterized by affecting the mucosal layer of the oropharyngeal route causing fibro-necrotic lesions (Hartati et al., 2021).

Vaccination with PPV is the cornerstone in the protection of pigeons against pigeon pox infection (Simon and Morten, 2011). Specific pathogen-free embryonated chicken egg (SPF-ECE) adapted pigeon pox virus (Hungarian strain) was used in Egypt to vaccinate pigeons against PP infection. More recently, Vero cell line culture adapted attenuated PPV local strain (Qalubia strain) was developed for the protection of pigeons against PP virus infection (Kaffafy et al., 2018). 
The Challenge test is considered the standard golden test for the evaluation of the potency of ECE adapted or tissue culture adapted PPV (Amina and Christine, 2020). Also, the virus neutralization test (VNT) is the main test for the evaluation of acquired humoral immunity measurement (OIE, 2019).

This study aims to assess the presence, duration, influence, and interference of maternal immunity induced by the recently developed live attenuated TC-PPV among squabs from vaccinated pigeons compared to non-vaccinated ones and determine the duration of acquired immune response in the vaccinated pigeon layer.

\section{MATERIALS AND METHODS}

\section{Pigeon pox vaccines:}

Tissue culture live attenuated Qalubia strain 2017 of PPV (TC- PPV) (Aboul Soud et al., 2018 and Kaffafy et al., 2018) with virus titer of $10^{5.5}$ $\mathrm{TCID}_{50} / \mathrm{ml}$ and SPF-ECE adapted PPV (Hungarian strain) (EG- PPV) with virus titer of $10^{6.0} \mathrm{EID}_{50} / \mathrm{ml}$ were kindly supplied by Pox Vaccines Research Department (PVRD), Veterinary Serum and Vaccine Research Institute (VSVRI), Abbasia, Cairo and used for vaccination of experimental birds by the feather follicle route according to Amina and Christine (2020).

\section{Challenge virus :}

Locally isolated PPV field isolate (Kaffafy $\boldsymbol{e t}$ al., 2015) kindly supplied by PVRD, VSVRI with virus titer of $10^{.6} \mathrm{EID}_{50} / \mathrm{ml}$ was used for the challenge of vaccinated and susceptible unvaccinated control pigeons by feather follicle route at the $3^{\text {rd }}$-week postvaccination. All birds were subjected to the daily observation of gross lesions and collection of serum samples.

\section{Susceptible pigeons:}

Seventy-five (75) susceptible laying pigeons of 90 days old were used in this study and divided into 3 groups (25 pigeons/group) as follow:

Group (1): vaccinated with tissue culture-adapted PPV 3 weeks before laying.

Group (2): vaccinated with egg adapted PPV 3 weeks before laying.

Group (3): included non-vaccinated laying pigeons.

Each group of offspring (40 squabs) of vaccinated groups 1 and 2 and non-vaccinated group (3) was divided into 8 subgroups (5 squabs/subgroup) as presented in table (1).
Table 1: Experimental design of squab's offspring:

\begin{tabular}{|c|c|c|c|c|c|c|}
\hline \multirow{2}{*}{ 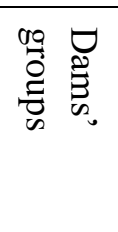 } & \multirow{2}{*}{ 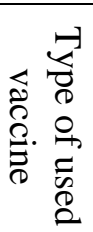 } & \multicolumn{4}{|c|}{$\begin{array}{l}\text { Days post-hatching } \\
\text { vaccination }(\mathrm{PHV})\end{array}$} & \multirow{2}{*}{ 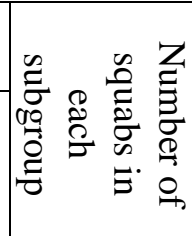 } \\
\hline & & 14 & 21 & 28 & 35 & \\
\hline \multirow{2}{*}{$\begin{array}{l}\text { Group } \\
(1)\end{array}$} & TC- & $\mathrm{A} 1$ & $\mathrm{~A} 2$ & A3 & A4 & \multirow{6}{*}{5 squabs } \\
\hline & PPV & B1 & B2 & B3 & B4 & \\
\hline \multirow{2}{*}{$\begin{array}{l}\text { Group } \\
(2)\end{array}$} & EG- & $\mathrm{C} 1$ & $\mathrm{C} 2$ & $\mathrm{C} 3$ & $\mathrm{C} 4$ & \\
\hline & PPV & D1 & D2 & D3 & D4 & \\
\hline \multirow{2}{*}{$\begin{array}{c}\text { Group } \\
\text { (3) }\end{array}$} & Non & E1 & E2 & E3 & E4 & \\
\hline & Non & F1 & $\mathrm{F} 2$ & F3 & F4 & \\
\hline
\end{tabular}

NB.: Subgroups A, B, C and D are offspring from vaccinated dams while subgroups $\mathrm{E}$ and $\mathrm{F}$ are offspring from non-vaccinated dams.

\section{Vero cell culture:}

The Vero cell line was kindly supplied by PVRD, VSVRI, propagated and maintained using Earle's Minimum Essential Medium (MEM) (Sigma Chemical Company, UK), and supplemented with 10 $\%$ newborn calf serum as a growth medium $2 \%$ as maintenance medium to be used in VNT.

\section{Pigeon pox hyper-immune sera:}

PPV hyper-immune serum was obtained from PVRD, VSVRI and used in VNT as a positive control.

\section{Serum samples:}

Serum samples were collected from all pigeons layers and squabs with weekly then monthly intervals kept at $-20{ }^{\circ} \mathrm{C}$ till subjected for detection of antibody levels by VNT.

\section{Virus neutralization test (VNT):}

Virus neutralization test (VNT) was done according to Kaffafy et al., (2018) and Amina and Christine (2020) for the detection of PPV antibodies in vaccinated layer pigeons and their squabs and Virus neutralization index (NI) was calculated according to the method described by Reed and Muench (1938).

\section{RESULTS}

\section{Post vaccinal reaction (takes) of pigeons vaccinated with TC-PPV and EA-PPV vaccines:}

The post-vaccinal reaction (takes) was detected at the site of follicle vaccination on the 3rd DPV and increased to its maximum at the 7th DPV reaching $88 \%$ for TC-PPV and $100 \%$ for EG-PPV, as shown in table (2). 
Table 2: Postvaccinal reaction in pigeon groups vaccinated by TC-PPV and EG- PPV:

\begin{tabular}{|c|c|c|c|c|}
\hline \multirow{2}{*}{$\begin{array}{c}\text { Pigeon } \\
\text { group }\end{array}$} & \multirow{2}{*}{$\begin{array}{c}\text { No. of } \\
\text { vaccinated } \\
\text { pigeon }\end{array}$} & \multicolumn{2}{|c|}{$\begin{array}{c}\text { Postvaccinal } \\
\text { reaction }\end{array}$} & \multirow{2}{*}{$\begin{array}{c}\text { Take } \\
\text { percent }\end{array}$} \\
\cline { 3 - 4 } & +VE & -VE & \\
\hline Group (1) & 25 & 22 & 3 & $88 \%$ \\
Group (2) & 25 & 25 & 0 & $100 \%$ \\
\hline
\end{tabular}

Group-1: vaccinated with TC-PPV .

Group-2: vaccinated with EG- PPV.

\section{Assessment of acquired immunity and its duration in vaccinated layer pigeons:}

The result of the virus neutralization test presented in table (3) and Fig. (1) and reveal that the level of protective PP antibodies (1.5) appeared 2 weeks post-vaccination (WPV) and the highest level (2.75) was at the $4^{\text {th }}$ WPV ( $\left.1 \mathrm{MPV}\right)$ and remained with a protective neutralizing index (1.5) till the $10^{\text {th }}$ month PV in group 1 vaccinated with TC-PPV while in group (2) vaccinated with EG- PPV the antibodies remained protective till the end of study (12 months PV) with NI (1.75) while unprotective NI was recorded in unvaccinated control pigeon.

Table 3: Virus Neutralization Index in vaccinated pigeons with TC-PPV and EG-PPV:

\begin{tabular}{|c|c|c|c|}
\hline \multirow{2}{*}{$\begin{array}{c}\text { Periods post- } \\
\text { vaccination }\end{array}$} & \multicolumn{3}{|c|}{$\begin{array}{c}\text { PP virus neutralization index } \\
\text { in pigeons' groups }\end{array}$} \\
\cline { 2 - 4 } & $\begin{array}{c}\text { Group } \\
(1)\end{array}$ & $\begin{array}{c}\text { Group } \\
(2)\end{array}$ & $\begin{array}{c}\text { Group } \\
(3)\end{array}$ \\
\hline Pre- & 0.50 & 0.25 & 0.50 \\
vaccination & & & 0.50 \\
\hline $1 \mathrm{WPV} *$ & 0.50 & 0.50 & 0.25 \\
$2 \mathrm{WPV}$ & 1.50 & 1.75 & 0.50 \\
$3 \mathrm{WPV}$ & 2.25 & 2.50 & 0.50 \\
$1 \mathrm{MPV} *$ & $2.75^{*}$ & $3.25^{*}$ & 0.25 \\
$2 \mathrm{MPV}$ & 2.75 & 3.25 & 0.50 \\
$3 \mathrm{MPV}$ & 2.50 & 3.0 & 0.25 \\
$4 \mathrm{MPV}$ & 2.25 & 2.75 & 0.50 \\
$5 \mathrm{MPV}$ & 2.25 & 2.75 & 0.25 \\
$6 \mathrm{MPV}$ & 2.00 & 2.75 & 0.50 \\
$7 \mathrm{MPV}$ & 1.75 & 2.25 & 0.25 \\
8 MPV & 1.75 & 2.25 & 0.50 \\
$9 \mathrm{MPV}$ & 1.5 & 2.00 & 0.50 \\
$10 \mathrm{MPV}$ & 1.5 & 2.00 & 0.25 \\
$11 \mathrm{MPV}$ & 1.25 & 1.75 & 0.50 \\
$12 \mathrm{MPV}$ & 1.25 & 1.75 & 0.5
\end{tabular}

$\mathrm{NI} \geq(1.5)$ is considered as positive protective results.Group-1: vaccinated with TC-PPV. Group-2: vaccinated with EG- PPV. Group-3: unvaccinated pigeon group. $* \mathrm{WPV}=$ week postvaccination. $* *$ MPV $=$ month postvaccination.

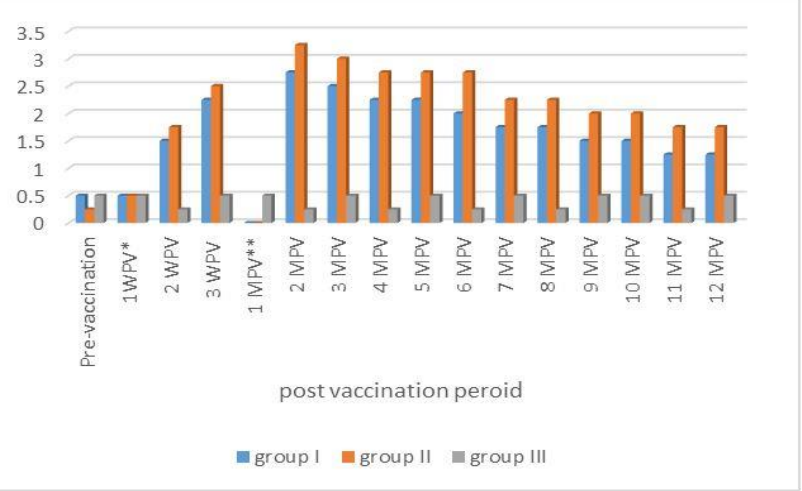

Fig. 1: Virus Neutralization Index in vaccinated pigeons with TC-PPV and EG-PPV.

3.Assessment of maternal immunity in squabs from vaccinated layer pigeon with PP vaccines:

The results of serum neutralization test carried out on serum samples obtained from squabs offspring of vaccinated pigeons with TC-PPV and EC-PPV as well as squabs offspring of non-vaccinated pigeons and challenged with virulent PPV at different intervals $(14,21,28$ and 35 days) post-hatching (PH) are represented in table (4). These results showed that protective levels of maternal immunity in the squabs offspring subgroup (A1, A2, A3 and A4) of pigeons vaccinated with TC-PPV (group-1) remained till the $3^{\text {rd }}$ WPV with protection percent $100 \%$ against challenge with virulent PP. Still, it decreased to $60 \%$ with unprotective NI at the $4^{\text {th }}$ WPH. In contrast, in subgroups $(\mathrm{C} 1, \mathrm{C} 2, \mathrm{C} 3$ and $\mathrm{C} 4)$, in offspring of pigeon vaccinated with EG-PPV (group-2), the protective level of NI continued up to the $4^{\text {th }}$ WPH with protection percent reaching $90 \%$ in contrast to pigeon offspring of non-vaccinated pigeon group (3) subgroup (E1, E2, E3 and E4) which had no protective antibodies with $0 \%$ protecting all over the experimental period.

Table 4: Duration of maternal immunity in squab's offspring of vaccinated pigeons with TC-PPV and EG-PPV using VNT:

\begin{tabular}{|c|c|c|c|c|c|c|c|c|c|}
\hline \multirow{2}{*}{$\underset{*}{\underset{*}{*}}$} & \multicolumn{3}{|c|}{ Group-1 } & \multicolumn{3}{|c|}{ Group-2 } & \multicolumn{3}{|c|}{ Group-3 } \\
\hline & $\begin{array}{l}\tilde{E} \\
\tilde{0} \\
\sigma 0 \\
0 \\
0 \\
0\end{array}$ & NI & $\mathrm{P} \%$ & $\begin{array}{l}\mathscr{E} \\
\tilde{E} \\
\sigma 0 \\
0 \\
\tilde{O}\end{array}$ & NI & $\mathrm{P} \%$ & $\begin{array}{l}\mathscr{E} \\
\tilde{\sigma} \\
\sigma 0 \\
0 \\
\tilde{\theta}\end{array}$ & NI & $\mathrm{P} \%$ \\
\hline 14 & A1 & 2.00 & 100 & $\mathrm{C} 1$ & 2.50 & 100 & E1 & 0.25 & 0 \\
\hline 21 & A2 & 1.50 & 100 & $\mathrm{C} 2$ & 2.00 & 100 & E2 & 0.50 & 0 \\
\hline 28 & A3 & 1.25 & 60 & $\mathrm{C} 3$ & 1.50 & 90 & E3 & 0.25 & 0 \\
\hline 35 & A4 & 1.25 & 0 & $\mathrm{C} 4$ & 1.25 & 40 & E4 & 0.50 & 0 \\
\hline
\end{tabular}

* $\mathrm{DPH}=$ days post-hatching . $\mathrm{P} \%$ : Protection Percent. Group-1: vaccinated with TC-PPV. Group-2: vaccinated with EG- PPV. Group-3: unvaccinated pigeons' group. 


\section{Evaluation for vaccination program with TC-PPV for squabs of vaccinated and non- vaccinated dams:}

Squabs offspring of vaccinated dams with TCPPV and EG-PPV as well as non-vaccinated dams were vaccinated with TC-PPV at different day intervals post-hatching $(14,21,28$ and $35 \mathrm{DPH})$ where the results of NI recorded $21 \mathrm{DPV}$ as well as the challenge presented in table (5) showed that squabs of vaccinated dams with TC-PPV at the 14 and $21 \mathrm{DPH}$ revealed an unprotective level of NI (1.0 and 1.2 respectively) and with protection\% 20\% and $40 \%$ against challenge with the virulent PP virus respectively. In contrast, protection $80 \%$ and NI (1.75) were obtained with vaccination at the $28 \mathrm{DPH}$, while in case of squabs of vaccinated dams with EG-PPV protection $(80 \%)$ was recorded at the $35 \mathrm{DPH}$ with protective NI (2.0). On the other side, squabs of unvaccinated dams and vaccinated at $14 \mathrm{DPH}$ with TC-PPV resulted in protection percent $100 \%$ with protective NI reaching (2.0).

Table 5: NI and protection\% in squabs of vaccinated and non-vaccinated dams and vaccinated with TC-PPV at different DPH:

\begin{tabular}{|c|c|c|c|c|c|c|c|c|c|}
\hline \multirow[b]{2}{*}{$\underset{*}{\underset{7}{\boldsymbol{T}}}$} & \multicolumn{3}{|c|}{ Group-1 } & \multicolumn{3}{|c|}{ Group-2 } & \multicolumn{3}{|c|}{ Group-3 } \\
\hline & 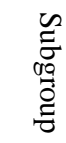 & NI & $\mathrm{P} \%$ & 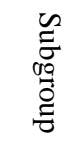 & NI & $\begin{array}{l}\mathrm{P} \\
\%\end{array}$ & 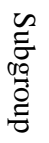 & NI & $\mathrm{P} \%$ \\
\hline 14 & B1 & 1.0 & 20 & D1 & 0.75 & 40 & F1 & 1.75 & 100 \\
\hline 21 & B2 & 1.25 & 40 & D2 & 1.25 & 40 & F2 & 2.00 & 100 \\
\hline 28 & B3 & 1.75 & 80 & D3 & 1.25 & 60 & F3 & 1.75 & 100 \\
\hline 35 & B4 & 2.0 & 100 & D4 & 2.00 & 80 & F4 & 2.00 & 100 \\
\hline
\end{tabular}

Subgroup (B1, B2, B3 and B4) offspring of dams vaccinated with TC-PPV.

Subgroup (D1, D2, D3 and D4) offspring of dams vaccinated with EC-PPV.

Subgroup (F1, F2, F3 and F4) offspring of unvaccinated dams.

\section{DISCUSSION}

The effective protection of pigeons from pigeon poxvirus infection is through vaccination with PPV (Tripathy and Reed, 2008) also, maternal immunity is the cornerstone in the protection of pigeons against infection in young squabs as it could affect and interfere with the vaccination programs against PPV. So, in this study, a maternally derived antibody (MDA) was studied to avoid its conflict with the PPV vaccination schedule.

At first, the duration of immunity induced by the recently developed TC-PPV was estimated in pigeons for the first time in long-term study reaching 1 year. The protective level of antibodies appeared on the $2^{\text {nd }}$ WPV with NI (1.5) reaching its highest level at the $1 \mathrm{MPV}$ with NI (2.75) and remaining protective till the $10^{\text {th }}$ MPV reaching (1.5). On the other hand, pigeons vaccinated with EG-PPV exhibited a longer duration of immunity till the end of this study (12 MPV) with (1.75) NI 2 WPV and (3.25) 1 MPV with a higher percent of postvaccinal reaction reaching $100 \%$ than obtained by TC-PPV (88\%).

Similar findings were obtained by Kaffafy $\boldsymbol{e} t$ al., (2018) when they evaluated the newly developed TC-PPV in a short-term study for 5 months where the highest level of antibodies reached (2.8) NI 1 month PV. Also, other results were obtained in a short-term study for 6 months by Amina and Christine (2020) comparing tissue culture adapted and egg adapted PPV and recorded a higher level of antibodies and post vicinal takes in pigeon group vaccinated by EGPPV than those obtained in pigeon group vaccinated with TC-PPV. So, depending on the previous results the ideal time of TC-PPV revaccination should not exceed 19 MPV.

Regarding the level of MDA of squabs from vaccinated dams with TC-PPV, the obtained resulted represented in table (4) showed that the protective level of MDA with NI reached (1.5) by the $3^{\text {rd }}$-week post-hatching (WPH) with protection percent against challenge with virulent PPV reaching $100 \%$ that decreased to $60 \%$ with $(1.25) \mathrm{NI}$ on the $4^{\text {th }} \mathrm{WPH}$. On the other hand, squabs obtained from vaccinated dams with EG-PPV showed protective MDA for $4 \mathrm{WPH}$ with (1.5) NI and protection percent $90 \%$ decreased to $60 \%$ and (1.25) NI 5 WPH. In contrast, unprotective values for $\mathrm{NI}$ and $0 \%$ of protection against challenge were obtained in control squabs from unvaccinated dams. These results reflected on the establishment of a vaccination program against PPV as shown in table (5) as vaccination of squabs from vaccinated dams with TC-PPV and EG-PPV up to $3 \mathrm{WPH}$ and $4 \mathrm{WPH}$ respectively with TC-PPV resulting in vaccination failure and unprotected level of NI (1.25) and 40\% protection and (1.25) and 60\% protection respectively while vaccination for these squabs with TC-PPV 4 WPH and 5 WPH showed succeed vaccination with (1.75) NI and (2.0) NI respectively and $80 \%$ and $100 \%$ protection against challenge.

On the other hand, vaccination of squabs unvaccinated dams with TC-PPV showed $100 \%$ protection by the $2^{\text {nd }}$ WPH with (1.75) NI that could be explained based on the interference and interaction of MDA against the used PPV as previously described by Taslema et al., (2008); Richard et al. (2016) and Nigist and Haben (2020) they reported that eggs are the source of passive immunity or maternal antibodies 
in poultry and remains effective for few weeks. When vaccines, especially live ones, were used during the first three weeks after hatching, where these MDA reached their peak, the vaccine will be neutralized. The level of antibodies of the new vaccine in hatched birds will be reduced resulting in vaccination failure. So, maternally derived antibody titers should be considered as vaccines should be administrated after MDA titration to ensure their disappearance.

\section{CONCLUSION}

This study estimated the long-term immunity of the newly developed TC-PPV up to 10 months. So, it could recommend the revaccination after this period. In addition, to avoid the passive interfere of maternal immunity exhibited by TC-PPV in squabs from vaccinated dams with TC-PPV, it recommends vaccinating them after $3 \mathrm{WPH}$ to ensure the disappearance of MDA avoiding vaccination failure.

\section{Declaration of Conflicting Interests}

The authors revealed that there is no potential conflicts of interest.

\section{REFERENCES}

ABDALLAH, F.M., and HASSANIN, O., 2013. Detection and molecular characterization of avipoxviruses isolated from different avian species in Egypt. Virus Genes Vol. 46, No: 1. P: 63-70. https://doi.org/10.1007/s11262-012-0821-y

ABOUL SOUD, A.E., OLFAT, E. NAKHLA, NAMAA, A. MOHAMED, EL SOALLY, S.A., and AYATOLLAH, I.I., 2018. Molecular and Antigenic Characterization of Pigeon Pox Virus Isolated in 2017. International Journal of Innovative Research \& Development (IJIRD), Vol. 7, Iss. 4, Pages: 219-231. https://doi.org/10.24940/ijird/2018/v7/i4/apr18091

AMINA, A. RADWAN and CHRISTINE, A. MIKHAEL, 2020. Comparative evaluation on the efficacy of embryonated chicken egg adapted and tissue culture Pigeon Pox vaccines against the local virulent strain. Journal Of Applied Veterinary Sciences, 5(2): 87-93.

https://doi.org/10.21608/javs.2020.85605

ANDRAW, K. 2012. Virus taxonomy: ninth report of the international committee on the taxonomy of viruses. The international committee on taxonomy of international union of microbiological societies. PP.298.

HARTATI, S., UNTARI, T., NURAINI, A.L., and NURURROZI, A., 2021. A case report of outbreak avian pox virus from layer chickens and a pigeon in Yogyakarta, Indonesia. Adv. Anim. Vet. Sci. 9(10): 1559-1563.

https://doi.org/10.17582/journal.aavs/2021/9.10.1559.1563

KAFFAFY, M.H., AHMED, H.A., ALI, A.S., MOHAMMED, A. ISMAEIL and MANAL, A., 2015. Isolation and Characterization of Pigeon Pox virus in Egypt. Ph.D. Thesis, (Virology) Faculty of Veterinary Medicine, Zagazig University.
KAFFAFY, M.H., ABOUL-SOUAD, E.A., OLFAT, E.N., CHRISTINE, A.M., and NERMIN, ME., 2018. Preliminary study on preparation and evaluation of a local isolate tissue culture propagated pigeon pox vaccine. VMJG Vol (46), PP 44- 50. https://doi.org/10.21608/vmjg.2018.156213

MEHMOOD, S., NASHIRUDDULLAH, N., and AHMED, J., 2021. Mortality in some domesticated pigeons (Columba livia) from Jammu, India Turkish Journal of Veterinary and Animal Sciences 45(1):158167. https://doi.org/10.3906/vet-1909-96

NIGIST, B., and HABEN, F., 2020. Vaccine Failure in Poultry Production and its Control Methods: A Review Biomed J Sci \& Tech Res Vol (29) Issue (4) PP: 22588-22596. https://doi.org/10.26717/bjstr.2020.29.004827

OIE., 2018. OIE Terrestrial Manual, chapter 3.3.10 Fowl pox. 906-913.

REED, L.J., and MUENCH, H., 1938. A simple method of estimating fifty percent endpoints. Am. J. Hyg, 27:493- 497.

RICHARD-MAZET, A., GOUTEBROZE, S., LE GROS, F. X., SWAYNE, D. E., and BUBLOT, M., 2014. Immunogenicity and efficacy of fowlpoxvectored and inactivated avian influenza vaccines alone or in a prime-boost schedule in chickens with maternal antibodies. Veterinary research, 45(1), 107. https://doi.org/10.1186/s13567-014-0107-6

TASLIMA, A., SHAHIDUR M., PAUL N., KAFI, A., SHIL, N., and SIDDIQUE M., 2008. Persistence of Maternally Derived Antibody in selected group of chicks to fowl pox virus. Bangladesh J. Micro., Vol. 25(1):57-59. http://dx.doi.org/10.3329/bjm.v25i1.4858.

TRIPATHY, D.N., and REED, W. M., 2008. Avian pox in Diseases of Poultry, 12th Ed., ed. by YM.

WELI, S.C., and TRYLAND, M., 2011. Avipoxviruses: infection biology and their use as vaccine vectors. Virol J., vol. 8,: 49-53(. https://doi.org/10.1186/1743$\underline{422 \mathrm{x}-8-49}$

How to cite this article:

Kafafy, M. H. and Ayatollah, I. Ibrahim, 2022. Effective Vaccination Program for Squabs from Vaccinated and NonVaccinated Pigeons with Tissue Culture Adapted Pigeon Pox Live Attenuated Vaccine Regarding Maternal Immunity. Journal of Applied Veterinary Sciences, 7 (1): 53 - 57.

DOI: 10.21608/javs.2021.104273.1113 